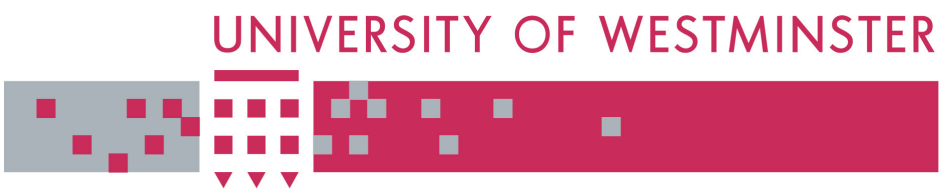

\title{
WestminsterResearch
}

http://www.wmin.ac.uk/westminsterresearch

\section{Yoga for depression: the research evidence}

\section{Karen Pilkington ${ }^{1,2}$ \\ Graham Kirkwood $^{1,3}$ Hagen Rampes ${ }^{4}$ Janet Richardson ${ }^{1,5}$}

${ }^{1}$ Research Council for Complementary Medicine, London, UK

${ }^{2}$ School of Integrated Health, University of Westminster, London, UK

${ }^{3}$ Health Services Research Department, Institute of Psychiatry, London, UK

${ }^{4}$ Barnet, Enfield \& Haringey NHS Mental Health Trust, Middlesex, UK

${ }^{5}$ Faculty of Health \& Social Work, University of Plymouth, UK

This is an electronic version of an article published in Journal of Affective Disorders, 89 (1-3). pp. 13-24, December 2005. The definitive version in the Journal of Affective Disorders is available online at:

http://www.sciencedirect.com/science/journal/01650327

The WestminsterResearch online digital archive at the University of Westminster aims to make the research output of the University available to a wider audience. Copyright and Moral Rights remain with the authors and/or copyright owners. Users are permitted to download and/or print one copy for non-commercial private study or research. Further distribution and any use of material from within this archive for profit-making enterprises or for commercial gain is strictly forbidden.

Whilst further distribution of specific materials from within this archive is forbidden, you may freely distribute the URL of WestminsterResearch.

(http://www.wmin.ac.uk/westminsterresearch).

In case of abuse or copyright appearing without permission e-mail wattsn@wmin.ac.uk. 
Yoga for depression: the research evidence

Karen Pilkington, Research Council for Complementary Medicine, London, UK and School of Integrated Health, University of Westminster, London, UK

Graham Kirkwood*, Research Council for Complementary Medicine, London, UK Hagen Rampes, Barnet, Enfield \& Haringey Mental Health NHS Trust, Northwest Community Mental Health Team, Edgware, Middlesex, UK

Janet Richardson, Faculty of Health and Social Work, University of Plymouth and Research Council for Complementary Medicine, London, UK

* now Health Services Research Department, Institute of Psychiatry, London, UK

Address for correspondence:

Karen Pilkington

Project Manager/Senior Research Fellow

School of Integrated Health

University of Westminster

115 New Cavendish Street

London W1W 6UW

United Kingdom

E-mail: k.pilkington@westminster.ac.uk

Tel no: 02079115000 ext 3920 


\section{Abstract}

\section{Background}

Yoga-based interventions may prove to be an attractive option for the treatment of depression. The aim of this study is to systematically review the research evidence on the effectiveness of yoga for this indication

\section{Methods}

Searches of the major biomedical databases including MEDLINE, EMBASE, CINAHL, PsycINFO and the Cochrane Library were conducted. Specialist complementary and alternative medicine (CAM) and the IndMED databases were also searched and efforts made to identify unpublished and ongoing research. Searches were conducted between January and June 2004. Relevant research was categorised by study type and appraised. Clinical commentaries were obtained for studies reporting clinical outcomes.

\section{Results}

Five randomised controlled trials were located, each of which utilised different forms of yoga interventions and in which the severity of the condition ranged from mild to severe. All trials reported positive findings but methodological details such as method of randomisation, compliance and attrition rates were missing. No adverse effects were reported with the exception of fatigue and breathlessness in participants in one study.

\section{Limitations}

No language restrictions were imposed on the searches conducted but no searches of databases in languages other than English were included.

\section{Conclusions}

Overall, the initial indications are of potentially beneficial effects of yoga interventions on depressive disorders. Variation in interventions, severity and 
reporting of trial methodology suggests that the findings must be interpreted with caution. Several of the interventions may not be feasible in those with reduced or impaired mobility. Nevertheless, further investigation of yoga as a therapeutic intervention is warranted.

Keywords: yoga, depression, depressive disorder, systematic review 


\section{Introduction}

Mental health problems such as depression, anxiety and insomnia are amongst the most common reasons for individuals to seek treatment with complementary therapies. Consequently, several surveys have been conducted which focus on this area.

Davidson and colleagues carried out a study to determine the frequency of psychiatric disorders in patients receiving complementary medical care in the UK and the USA (Davidson et al., 1998). The authors found that psychiatric disorders were relatively frequent. Based on rates of lifetime psychiatric diagnoses, a total of $74 \%$ of the British patients and $60.6 \%$ of the American patients had a diagnosis. Major depression (52\% of UK and $33.3 \%$ of USA) and any anxiety disorders (50\% of UK and $33.3 \%$ of USA) were the commonest lifetime diagnoses. Rates of current psychiatric disorder were $46 \%$ of the UK patients and $30.3 \%$ of the USA patients. Six per cent of the total suffered from major depression and $25.3 \%$ of the total met the criteria for at least one anxiety disorder.

Unutzer et al. (2000) used data from a national household telephone survey conducted in 1997-98 in the USA to examine the relationship between mental disorders and the use of complementary therapies. The sample of 14,985 included those reporting psychological distress or mental health service use in addition to non-distressed nonusers. Analysis of the 9,585 completed interviews indicated a high rate of use of complementary therapies in adults who met criteria for common psychiatric disorders. $22.4 \%$ of respondents who met the criteria for major depression had used complementary and alternative medicine during the past 12 months. A similar survey of a nationally representative sample of 2055 respondents revealed that $7.2 \%$ reported suffering from "severe depression" (Kessler et al., 2001). A total of $53.6 \%$ of those with severe depression reported using complementary and alternative medicine for treatment in the past 12 months. 
A trend towards increasing use of complementary therapies among people with major depression was demonstrated by a study conducted in Canada (Wang et al., 2001). Analysis of data from the National Population Health Surveys indicated that the prevalence of use in those with major depression was $7.8 \%$ (19.4\% including chiropractic) in 1994-95 and 12.9\% (23.8\% including chiropractic) in 1996-97. Finally, the findings of a recent Australian postal survey of 6618 randomly selected adults suggested that self-help strategies including complementary therapies were very commonly used to cope with depression, particularly in mild-moderate psychological distress (Jorm et al., 2004).

A range of therapeutic approaches are available for the management of depressive disorders but patients may turn to complementary therapies due to adverse effects of medication, lack of response or simply preference for the complementary approach.

\section{Yoga}

Yoga has its origins in Indian culture and in its original form consisted of a complex system of spiritual, moral and physical practices aimed at attaining 'selfawareness'. Hatha yoga, the system on which much of Western yoga is based has 3 basic components, asanas (postures), pranayama (breathing exercises) and dhyana (meditation). The postures involve standing, bending, twisting and balancing the body and consequently improve flexibility and strength. The controlled breathing helps to focus the mind and achieve relaxation while meditation aims to calm the mind (Riley, 2004). Although yoga has its origins in Indian religion, it can be practised secularly and has been used clinically as a therapeutic intervention. Several explanations based on Western physiology have been proposed to account for potential effects of yoga in the treatment of various conditions. These can be summarised as modulation of autonomic nervous tone and consequent reduction in sympathetic tone, activation of antagonistic neuromuscular systems, which may increase the relaxation 
response in the neuromuscular system, and stimulation of the limbic system primarily by meditation (Riley, 2004).

A national survey conducted in the US demonstrated that $7.5 \%$ of respondents had used yoga at least once in their lifetime and $3.8 \%$ had used it in the previous year. Users were more likely to be female, college educated and urban dwellers and use was for both wellness and specific health conditions (Saper et al., 2004). The authors point out that despite greater prevalence of use than other CAM therapies such as acupuncture and homeopathy, yoga receives less coverage in the Western biomedical literature. Additionally, many of the trials of yoga are small and the results difficult to generalise.

However, a recent bibliometric analysis has demonstrated an increase in publication frequency of research on the clinical application of yoga and growing use of randomised controlled trials (Khalsa, 2004). Clinical trials were located on the use of yoga for depression, anxiety, cardiovascular conditions (e.g. hypertension, heart disease), respiratory problems (e.g. asthma), diabetes and a variety of others. Systematic reviews of these trials have not yet been conducted although a systematic review of trials of yoga in epilepsy (Ramaratnam and Sridharan, 2000) concluded that insufficient robust evidence was available. No systematic reviews of yoga in depression have been published.

\section{Aim and objectives}

The aim of this study was to evaluate the evidence on the effectiveness of yoga for the treatment of depression 


\section{Methods}

\section{Summary of the search strategy}

A comprehensive search for clinical research was carried out. Systematic searches were conducted on a range of databases, citations were sought from relevant reviews and several websites were also included in the search, including those of MIND and the Mental Health Foundation.

\section{Databases searched}

General databases:

CINAHL, Cochrane Central Register of Controlled Trials (CENTRAL), Cochrane Database of Systematic Reviews, Database of Abstracts of Reviews of Effects, EMBASE, IndMED (Indian Medlars Centre), MEDLINE (and PubMed), PsycINFO.

Specialist CAM and condition based databases:

AMED, CISCOM, Cochrane Depression, Anxiety and Neurosis (CCDAN) Review Group register.

Yoga websites:

International Association of Yoga Therapists (http://iayt.org/)

Yoga Biomedical Trust (http://www.yogatherapy.org/)

Yoga Research and Education Center (http://www.yrec.org/)

All searches, except that of the CCDAN register and IndMED, were conducted between January to June 2004 and covered databases from their inception. The CCDAN register was searched in December 2004 and IndMED was searched in July 2005. 


\section{Search terms}

The basic search terms for yoga were Yoga/ or Yoga.mp or Yogic.mp or Pranayama.mp or Dhyana.mp or Asanas.mp Terms for depression were Exp depression or Exp depressive disorder(s) or Exp dysthymia or Exp dysthymic disorder(s) or Depress* or Dysthym* or Exp affective disorder(s) Additional terms used as required included Yog ${ }^{*}$, Affective, Depressi ${ }^{\star}$, Mood

Search strategies were adapted for each of the databases searched. Efforts were made to identify unpublished and ongoing research using relevant databases such as the National Research Register (UK) and Clinicaltrials.gov (US).

\section{Filtering}

Relevant research was categorised by study type according to a flow-chart system developed for this project. Animal research and basic lab-based research were not included in the categorisation process.

\section{Selection criteria}

Types of studies

All clinical studies, whether controlled trials, uncontrolled studies or observational studies, were identified. Only randomised controlled studies were selected for inclusion in this review. Abstracts were excluded. Attempts were also made to locate relevant qualitative studies.

No language restrictions were imposed the search and filtering stage and translations would have been obtained for any potentially relevant studies in languages other than English.

Types of participants

Participants with depression or a depressive disorder. 
Types of intervention

Yoga and yoga-based exercises. Studies that involved interventions based solely on meditation and those involving complex or multiple interventions (e.g. MBSR mindfulness based stress reduction programmes) were excluded.

Types of outcome measures

Depression rating scales

\section{Data collection and analysis}

Data was extracted systematically using a specially designed data extraction form. Data extracted included details of selection criteria and procedure, the participants, the intervention and any comparison or control intervention, aspects of the methodology and outcome measures and results.

Clinical trials were appraised using a standardised appraisal framework specifically developed for this project and based on criteria recommended in the Centre for Reviews and Dissemination Report Undertaking Systematic Reviews of Research on Effectiveness (2001). Criteria included method of randomisation, allocation concealment and level of blinding (if relevant), baseline comparison of characteristics, method of dealing with missing values, loss to followup/withdrawals, measures of compliance and outcomes measures reported. For each study, data extraction and appraisal were conducted independently by two researchers and any disagreements or discrepancies were resolved by discussion. Where consensus could not be obtained, a third reviewer was available for consultation.

\section{Clinical commentaries}

Clinicians with relevant training and experience were asked to comment on each study focusing on clinical relevance and practical issues. Commentary frameworks were specifically developed for this project and these incorporate a 
number of closed and open questions with space for further comments.

Summaries of these commentaries are provided in the table of studies (Table 1).

\section{Main results}

Searches of the databases resulted in a total of 342 citations for initial screening (numbers do not include searches of the yoga websites). Screening resulted in the identification of 35 potential clinical trials, which were retrieved for closer examination. Of these, 30 did not meet the inclusion criteria and these are listed below together with the reasons for exclusion.

A total of 5 randomised controlled trials are included in this review (Broota and Dhir, 1990, Janakiramaiah et al., 2000, Khumar et al., 1993, Rohini et al., 2000, Woolery et al., 2004), each of which utilised different forms of yoga interventions. These trials are presented in Table 1 together with an appraisal of the reported methodology and comments on clinical relevance. No studies in languages other than English were located.

Excluded studies:

\begin{tabular}{|l|l|}
\hline Study & Reason for exclusion \\
\hline Girodo, 1974, Janakiramiah et al., & No control group \\
1998, Kaye 1985, Kessell, 1994, \\
Naga Venkatesha Murthy et al., \\
1997 and 1998
\end{tabular}




\begin{tabular}{|c|c|}
\hline & $\begin{array}{l}\text { general mood, no specific measure } \\
\text { of depression }\end{array}$ \\
\hline Sridevi and Krishna Rao, 1996 & $\begin{array}{l}\text { Menstrual distress, no specific } \\
\text { measure of depression }\end{array}$ \\
\hline $\begin{array}{l}\text { Bedard et al., } 2003 \text { (brain injuries); } \\
\text { Galantino et al., } 2004 \text { (back pain); } \\
\text { Manocha et al., } 2002 \text { (asthma); } \\
\text { Massion et al., } 1997 \text { (cancer); Oken } \\
\text { et al., } 2004 \text { (multiple sclerosis); } \\
\text { Robinson et al., } 2003 \text { (HIV) }\end{array}$ & $\begin{array}{l}\text { Primary focus on treatment of } \\
\text { medical/physical condition and } \\
\text { levels of depression measured as } \\
\text { one of range of outcomes }\end{array}$ \\
\hline Cohen et al., 2004 (cancer) & $\begin{array}{l}\text { Focus on psychological outcomes } \\
\text { but low depression scores at } \\
\text { baseline }\end{array}$ \\
\hline Shapiro et al., 2003 (cancer) & $\begin{array}{l}\text { Primary outcome measure sleep } \\
\text { disturbance not depression }\end{array}$ \\
\hline Platania-Solazzo et al., 1992 & $\begin{array}{l}\text { Complex intervention - yoga, } \\
\text { massage and progressive } \\
\text { muscular relaxation }\end{array}$ \\
\hline Shapiro et al., 1998 & $\begin{array}{l}\text { MBSR not yoga (and in healthy } \\
\text { volunteers) }\end{array}$ \\
\hline Teasdale et al., 2000 & $\begin{array}{l}\text { Mindfulness-based cognitive } \\
\text { therapy not yoga }\end{array}$ \\
\hline Monti unpublished (cancer) & $\begin{array}{l}\text { Mindfulness-based art therapy not } \\
\text { yoga }\end{array}$ \\
\hline Speca et al., 2000 (cancer) & $\begin{array}{l}\text { Focus on psychological outcomes } \\
\text { but MBSR not yoga }\end{array}$ \\
\hline
\end{tabular}

\section{Summary of the studies}


Broota and Dhir (1990) reported the results of a randomised controlled trial of two relaxation techniques, one of which is adapted from yoga, in 30 outpatients diagnosed with mainly neurotic or reactive depression and selected by a psychiatrist. Broota relaxation (yoga-based) and Jacobson's progressive relaxation technique were compared against the control intervention, which was to narrate present complaints and state of mind. The interventions were given for short periods over 3 consecutive days. Limited methodological details are reported: the method of randomisation is unknown and a baseline comparison of groups was not reported. Positive results were obtained for both treatment groups compared with the control intervention. The Broota technique was reported to be more effective. However, outcomes were based on percentage symptom reduction measured using a symptom checklist developed for the trial, completed by the patient before and after each session. As blinding was not feasible and the outcomes self-reported, some bias is likely to have been introduced. The attrition rate was low (1 patient per group) but this would be expected with a short intervention such as this. No difficulties with these programmes or with associated adverse effects with the exception of fatigue were reported. However, as the participants were all under 50 years of age, there are some limitations with generalising the results to the wider population.

The effectiveness of Shavasana, which consists of rhythmic breathing and relaxation, has been studied in cases of severe depression (Khumar et al., 1993). A total of 50 female university students were randomised to either a group that practised Shavasana for 30 minutes daily for 30 days or to a group that received no intervention. The Amritsar Depression Inventory and Zung Depression Self Rating Scale were used for the initial diagnosis and the latter scale was also used as one of the outcome measures. There was a significant reduction in depression score mid and post treatment for the yoga group but not for the control group. A between group comparison was non-significant at pre-treatment but had reached significance at mid and post treatment. There were no adverse 
effects. However, as with the previous study, basic details of the methodology were not reported including loss to follow up and withdrawals.

Janakiramaiah et al. (2000) conducted a triple arm RCT involving 45 patients with a DSM-IV diagnosis of melancholic depression (score of 17+ on Hamilton Rating Scale for Depression) recruited consecutively. The three interventions were Sudarshan Kriya Yoga (SKY), ECT (electroconvulsive therapy) and drug therapy (imipramine) for 4 weeks. SKY consists of 3 sequential components based on specified rhythms of breathing. Significant reductions in Beck Depression Inventory (BDI) and Hamilton Rating Scale for Depression (HRSD) for all 3 groups were achieved and although the response to SKY did not match that achieved with ECT, it was comparable to that achieved with drug therapy. Respective remission rates were SKY 67\%, ECT 93\% and drug therapy $73 \%$. Again various methodological details, such as method of randomisation, are unknown. No adverse effects were reported.

SKY was also the subject of a study by Rohini et al. (2000). The inclusion criteria and size of the study were similar to those of the study by Janakiramaiah et al. (2000). Thirty participants, each with major depressive disorder (DSM-IV, score of 18+ on HRSD), were enrolled in the study. The overall aim was to compare full SKY against partial SKY (full SKY without cyclical breathing). Concealment of allocation and blinding of assessors on this occasion were adequate and positive results were still obtained with a non-significant reduction in total scores for both groups. However, more full SKY than partial SKY responded based on $50 \%$ or greater reduction in $\mathrm{BDI}$ total scores.

In the most recent study, Woolery et al. (2004) tested a short-term course of lyengar yoga in patients with mild depression as measured using BDI (scores of 10-15) but without a psychiatric diagnosis. lyengar yoga is based on the teachings of B.K.S. Iyengar who considered specific asanas and sequences of asanas to be particularly effective for alleviating depression. The asanas 
recommended are those that involve opening and lifting of the chest, inversions and vigorous standing poses. The 28 adult volunteers, all aged less than 30 years were randomly assigned to two 1-hour yoga classes each week for 5 weeks or to a waiting list control group. Methods of randomisation, allocation concealment and blinding of assessors were not reported. A total of 5 patients withdrew ( 3 out of 13 in the yoga group, 2 out of 15 in the control group), a significant proportion in a small trial such as this and the reasons were not given. However, a significant reduction in BDI and State Trait Anxiety Inventory (STAI) was observed in the yoga but not in the control group who had received no intervention. The effects emerged by the middle of the course and were maintained at the end.

From the findings of these studies it appears that yoga-based interventions may have potentially beneficial effects on depressive disorders. However, several aspects require consideration. Firstly, the interventions varied incorporating a variety of asanas and/or breathing exercises. Therefore, it is not possible to assess which of these interventions or which aspect of each intervention is most effective. The yoga methods used were well-described with the exception of the two studies of SKY. For a full description of SKY, the authors of these papers direct the reader to either previous reports or a demonstration video (Janakiramiah et al., 2000; Rohini et al., 2000). Rhythmic breathing did, however, form an important component of the intervention in 4 of the trials (Broota and Dhir, 1990; Janakiramiah et al., 2000; Khumar et al., 1993; Rohini et al., 2000). Secondly, the levels of depression being treated ranged from mild to severe with different measures being used to diagnose and/or assess severity. Finally, basic details of trial methodology were not reported. Thus, methods of randomisation are unknown and while it is not possible to blind participants or care givers to the intervention, blinding of assessors takes on a greater significance and was either not ensured or not reported except in one study (Rohini et al, 2000). Consequently, the findings must be interpreted with caution and for this reason, a meta-analysis was not considered appropriate. 
Other considerations include the feasibility of some of the interventions in the older patient or those with reduced or impaired mobility. Adverse effects were not reported with the exception of breathlessness and fatigue in those who had not previously exercised in one study (Broota and Dhir, 1990) but the participants in two of the studies were less than 30 years of age (Khumar et al., 1993 and Woollery et al., 2004) and none of the participants in the yoga interventions in any study were over 50 years of age. With regard to other potential safety issues, a brief survey of published literature reveals that a small number of cases of adverse psychological effects have been reported (Hansen,1980; Yorston, 2001) although these appear to be related specifically to meditation. Other reports of single cases have suggested that serious adverse events are possible (e.g. Hanus et al. 1977, Vogel et al., 1991 Mattio et al., 1992, Margo et al., 1992, Fong et al., 1993, Cohen et al.,1995 Biswas et al., 2002, Johnson et al., 2004). However, these problems are likely to be rare based on the limited number of case reports in the literature. Nevertheless, in the absence of systematic evaluations of the risks and while practice of yoga is often without the knowledge of the health care professional, any adverse events are likely to be underreported and any risks difficult to assess. The recommendation that any exercise programme should only be undertaken on the advice of a health professional appears reasonable.

The final consideration is related to compliance and motivation of those with depression to participate in programmes such as those reported in these trials. Low levels of attrition were reported in 2 studies (Broota and Dhir, 1990; Woolery et al., 2004) but attrition rate was not reported in the remaining studies, therefore it is difficult to comment on this aspect. An exploratory study by Grover and colleagues (1989) of 186 'neurotic' patients compared those who completed a 46 week yoga programme with those who dropped out before completion. The only difference between dropouts and nondropouts was in the severity of illness at intake, with those with more severe symptoms being more likely to continue 
with the programme. Initial attitude to yoga was not a contributory factor. This study was conducted some time ago and in view of the lack of qualitative studies in this field, a further exploration of this aspect particularly related to those participating in programmes in a range of contexts would probably prove valuable. However, even with conventional management such as drug therapy, discontinuation of treatment for depression is a considerable problem; Linden et al. (2000) reported rates of termination of antidepressant treatment of between $31-48 \%$ in the first 10 weeks while Lawrenson et al. (2000) reported that over $50 \%$ of patients had ceased treatment in the first 6 weeks.

\section{Conclusions}

Overall, the initial indications are of potentially beneficial effects of yoga interventions on depressive disorders. However, variation in the interventions utilised and in the severity of the depression reported was encountered in the studies located together with a lack of details of trial methodology. Consequently, the findings must be interpreted with caution. A further consideration is that of the feasibility of some of the interventions in those with reduced or impaired mobility as the majority of participants in the studies were young and relatively fit. Nevertheless, yoga-based interventions may prove to be an attractive option for the treatment of depressive disorders. As highlighted previously, yoga is nonpharmacological, appears to have minimal adverse effects if practised as recommended and enjoys international acceptance (Ramaratnam and Sridharan, 2000). Thus further investigation of yoga as a therapeutic intervention in depressive disorders is warranted.

The aim of future studies should be to identify which of the potential yoga-based interventions is most effective and what levels of severity of depression are likely to respond to this approach. Systematic reviews on the effect of exercise in general on depression have reported differing conclusions: Craft and Perna, 2004 and North et al., 1990 concluding that exercise results in overall benefit while Lawlor and Hopker (2001) concluded that the evidence was insufficient. 
This topic is currently being revisited as a Cochrane review is in preparation (Lawlor and Campbell, 2000). The recent NICE guidance on the management of depression provides support for "structured and supervised exercise" particularly in those with mild to moderate depression (NICE, 2004). Consequently, an assessment of the comparative effectiveness of anaerobic exercise (such as yoga) and aerobic exercise in depressive disorders, both in the short and long term would also prove valuable.

\section{Acknowledgements}

Anelia Boshnakova, Electronic Information Officer, RCCM for advice and support with search strategies and searches.

Hugh McGuire, CCDAN Trials Search Coordinator for the Cochrane Depression, Anxiety and Neurosis Review Group for conducting searches on the CCDAN trial register.

The Project Advisory Group and Specialist Advisory Group (mental health) for the NHS Priorities Project for advice and support to the project.

The NHS Priorities Project is funded by the Department of Health. The views and opinions expressed are those of the authors and do not necessarily reflect those of the Department of Health.

\section{References}

Bedard, M., Felteau, M., Mazmanian, D., Fedyk, K., Klein, R., Richardson, J., Parkinson, W., Minthorn-Biggs, M.B., 2003. Pilot evaluation of a mindfulnessbased intervention to improve quality of life among individuals who sustained traumatic brain injuries. Disabil. Rehabil. 25(13), 722-731. 
Berger, B.G., Owen, D.R., 1992. Mood alteration with yoga and swimming: aerobic exercise may not be necessary. Percept. Mot. Skills 75,1331-1343.

Berger, B.G., Owen, D.R., 1988. Stress reduction and mood enhancement in four exercise modes: Swimming, body conditioning, hatha yoga, and fencing. Res. Q. Exerc. Sport 59 (2), 148-159.

Biswas, R., Paul, A., Shetty, K.J., 2002. A yoga teacher with persistent reflux symptoms. Int. J. Clin. Pract. 56, 723.

Blumenthal, J.A., Emery, C.F., Madden, D.J., George, L.K., Coleman, R.E., Riddle, M.W., McKee, D.C., Reasoner, J., Williams, R.S., 1989. Cardiovascular and behavioral effects of aerobic exercise training in healthy older men and women. J. Gerontol. 44(5), M147-57.

Blumenthal, J.A., Emery, C.F., Madden, D.J., Schniebolk, S., Walsh-Riddle, M., George, L.K., McKee, D.C., Higginbotham, M.B., Cobb, F.R., Coleman, R.E., 1991. Long-term effects of exercise on psychological functioning in older men and women. J. Gerontol. 46(6), P352-361.

Broota, A., Dhir, R., 1990. Efficacy of two relaxation techniques in depression. J. Pers. Clin. Stud. 6 (1), 83-90.

Centre for Reviews and Dissemination (CRD), 2001. Undertaking Systematic Reviews of Research on Effectiveness. Report Number 4 ( $2^{\text {nd }}$ Edition) CRD, York.

Cohen, J.A., Char, D.H., Norman, D., 1995. Bilateral orbital varices associated with habitual bending. Arch. Ophthal. 113, 1360-1362. 
Cohen, L., Warneke, C., Fouladi, R.T., Rodriguez, M.A., Chaoul-Reich, A., 2004. Psychological adjustment and sleep quality in a randomized trial of the effects of a Tibetan yoga intervention in patients with lymphoma. Cancer 100, 2253-2260.

Craft, L.L., Perna, F.M., 2004. The Benefits of Exercise for the Clinically Depressed. Prim Care Companion J Clin Psychiatry 6(3), 104-111.

Davidson, J.R., Rampes, H., Eisen, M., Fisher, P., Smith, R.d., Malik, M., 1998. Psychiatric disorders in primary care patients receiving complementary medical treatments. Compr. Psychiatry 39 (1),16-20.

Fong, K.Y., Cheung, R.T., Yu, Y.L., Lai, C.W., Chang, C.M., 1993. Basilar artery occlusion following yoga exercise: a case report. Clin. Exp. Neurol. 30, 104-109.

Galantino, M.L., Bzdewka, T.M., Eissler-Russo, J.L., Holbrook, M.L., Mogck, E.P., Geigle, P., Farrar, J.T., 2004. The impact of modified Hatha yoga on chronic low back pain: a pilot study. Altern. Ther. Health Med. 10(2), 56-59.

Girodo, M., 1974. Yoga meditation and flooding in the treatment of anxiety neurosis. J. Behav. Ther. Exp. Psychiatry 5(2), 157-160.

Grover, P., Varma, V.K., Verma, S.K., Pershad, D., 1989. Factors influencing treatment acceptance in neurotic patients referred for yoga therapy: An exploratory study. Indian J. Psychiatry 31(3), 250-257.

Hansen, W., 1980. Psychoses and meditation. [Danish]. Ugesk. Laeger143(1), 20-22.

Hanus, S.H., Homer, T.D., Harter, D.H., 1977. Vertebral artery occlusion complicating yoga exercises. Arch. Neurol. 34, 574-575. 
Harvey, J.R., 1983. The effect of yogic breathing exercises on mood. J. Am. Soc. Psychosom. Dent. Med. 30(2), 39-48.

Janakiramaiah, N., Gangadhar, B.N., Naga Venkatesha Murthy, P.J., Harish, M.G., Shetty, K.T., Subbakrishna, D.K., Meti, B.L., Raju, T.R., Vedamurthachar, A., 1998. Therapeutic efficacy of Sudarshan Kriya Yoga (SKY) in dysthymic disorder. NIMHANS J. 16(1), 21-28.

Janakiramaiah, N., Gangadhar, B.N., Naga Venkatesha Murthy, P.J., Harish, M.G., Subbakrishna, D.K., Vedamurthachar, A., 2000. Antidepressant efficacy of Sudarshan Kriya Yoga (SKY) in melancholia: a randomized comparison with electroconvulsive therapy (ECT) and imipramine. J. Affect. Disord. 57, 255-259.

Johnson, D.B. Tierney, M.J. Sadighi, P.J., 2004. Kapalabhati pranayama: breath of fire or cause of pneumothorax? A case report. Chest 125, 19511952.

Jorm, A.F., Griffiths, K.M., Christensen, H., Parslow, R.A., Rogers, B., 2004. Actions taken to cope with depression at different levels of severity: a community survey. Psychol. Med. 34, 293-299.

Kawano, R., 1999. The Effect of Exercise on Body Awareness and Mood. Thesis. Michigan State U., US.

Kaye, V.G., 1985. An innovative treatment modality for elderly residents of a nursing home. Clin. Gerontol. 3(4), 45-51.

Kessell, M,J., 1994. Women's adventure group: Experiential therapy in an HMO setting. Women Ther. 15(3-4), 185-203. 
Kessler, R.C., Soukup, J., Davis, R.B., Foster, D. F. Wilkey, S. A. Van Rompay, M. I., Eisenberg, D. M., 2001. The use of complementary and alternative therapies to treat anxiety and depression in the United States. Am J Psychiatry 158, 289-294.

Khalsa, S.B., 2004. Yoga as a therapeutic intervention: A bibliometric analysis of published research studies. Indian J. Physiol. Pharmacol. 48 (3), 269-285.

Khasky, A.D., Smith, J.C., 1999. Stress, relaxation states, and creativity. Percept. Mot. Skills 88, 409-416.

Khumar, S.S., Kaur, P., Kaur, S., 1993. Effectiveness of Shavasana on depression among university students. Ind. J. Clin. Psychol. 20 (2), 82-87.

Lawlor, D., Campbell, P., 2000. Exercise for depression. The Cochrane Database of Systematic Reviews, Issue 2. Art. No.: CD004366. DOI: 10.1002/14651858.CD004366.

Lawlor, D.A., Hopker, S.W., 2001. The effectiveness of exercise as an intervention in the management of depression: systematic review and metaregression analysis of randomised controlled trials. BMJ 322, 763-767.

Lawrenson, R.A., Tyrer, F., Newson, R.B., Farmer, R.D., 2000. The treatment of depression in UK general practice: selective serotonin reuptake inhibitors and tricyclic antidepressants compared. J. Affect. Disord. 59, 149-157.

Linden, M., Gothe, H., Dittmann, R.W., Schaaf, B., 2000. Early termination of antidepressant drug treatment. J. Clin. Psychopharmacol. 20, 523-530. 
Manocha, R., Marks, G.B., Kenchington, P., Peters, D., Salome, C.M., 2002. Sahaja yoga in the management of moderate to severe asthma: a randomised controlled trial. Thorax 57, 110-115.

Margo, C.E., Rowda, J., Barletta, J., 1992. Bilateral conjunctival varix thromboses associated with habitual headstanding. Am. J. Ophthalmol. 113, 726-727.

Massion, A.O., Herbert, J.R., Clemow L., Wertheimer, Kabat-Zinn, J., 1997. New research in psychosocial interventions for women with early stage breast cancer: The Bridges Study. (Meeting abstract). American Psychiatric Association,150th Annual Meeting, San Diego.

Mattio, T.G., Nishida, T., Minieka, M.M., 1992. Lotus neuropathy: report of a case. Neurology 42, 1636.

Monti, D.A. (unpublished) Mindfulness-Based Art Therapy for Cancer Patients. (Accessed 25 Feb 2005). Available from: http://www.clinicaltrials.gov/ct/show/NCT00034970?order=1

Naga Venkatesha Murthy, P.J., Janakiramaiah, N., Gangadhar, B.N., Subbakrishna, D.K., 1998. P300 amplitude and antidepressant response to Sudarshan Kriya Yoga (SKY). J. Affect. Disord. 50 (1), 45-48.

Naga Venkatesha Murthy, P.J., Gangadhar, B.N., Janakiramaiah, N., Subbakrishna, D.K., 1997. Normalization of P300 amplitude following treatment in dysthymia. Biol. Psychiatry 42(8), 740-743.

Netz, Y., Lidor, R., 2003. Mood alterations in mindful versus aerobic exercise modes. J. Psychol. 137, 405-419. 
NICE (National Institute for Clinical Excellence), 2004. CG23 Depression: management of depression in primary and secondary care. National Institute for Clinical Excellence and the National Collaborating Centre for Mental Health, London.

North, T.C., McCullagh, P., Tran, Z.V., 1990. Effect of exercise on depression. Exerc. Sport. Sci. Rev. 18, 379-415.

Oken, B.S., Kishiyama, S., Zajdel, D., Bourdette, D., Carlsen, J., Haas, M., Hugos, C., Kraemer, D.F., Lawrence, J., Mass, M., 2004. Randomized controlled trial of yoga and exercise in multiple sclerosis. Neurology 62, 2058-2064.

Platania-Solazzo, A., Field, T.M., Blank, J., Seligman, F., Kuhn, C., Schanberg, S., Saab, P., 1992. Relaxation therapy reduces anxiety in child and adolescent psychiatric patients. Acta Paedopsychiatr. 55 (2),115-120.

Ramaratnam, S., Sridharan, K., 2000. Yoga for epilepsy. The Cochrane Database of Systematic Reviews, Issue 1. Art. No.: CD001524. DOI:10.1002/14651858.CD001524.

Ray, U.S., Mukhopadhyaya, S., Purkayastha, S.S., Asnani, V., Tomer, O.S., Prashad, R., Thakur, L., Selvamurthy, W., 2001. Effect of yogic exercises on physical and mental health of young fellowship course trainees. Indian J. Physiol. Pharmacol. 45(1), 37-53.

Riley, D., 2004. Hatha yoga and the treatment of illness (commentary). Altern. Ther. Health Med. 10 (2), 20-21.

Robinson, F.P., Mathews, H.L., Witek-Janusek, L., 2003. Psycho-endocrineimmune response to mindfulness-based stress reduction in individuals infected 
with the human immunodeficiency virus: a quasiexperimental study. J. Altern. Complement. Med. 9, 683-694.

Rohini, V., Pandey, R.S., Janakiramaiah, N., Gangadhar, B.N., Vedamurthachar, A., 2000. A comparative study of full and partial Sudarshan Kriya Yoga (SKY) in major depressive disorder. NIMHANS J.18 (1-2), 53-57.

Saper, R.B., Eisenberg, D.M., Davis, R.B., Culpepper, L., Phillips, R.S., 2004. Prevalence and patterns of adult yoga use in the United States: results of a national survey. Altern. Ther. Health Med. 10 (2), 44-49.

Schell, F.J., Allolio, B., Schonecke, O.W., Physiological and psychological effects of Hatha-Yoga exercise in healthy women. Int. J. Psychosom. 41 (1-4), 46-52.

Shapiro, S.L., Bootzin, R.R., Figueredo, A.J., Lopez, A.M., Schwartz, G.E., 2003. The efficacy of mindfulness-based stress reduction in the treatment of sleep disturbance in women with breast cancer. An exploratory study. J. Psychosom. Res. 54(1), 85-91.

Shapiro, S.L., Schwartz, G.E., Bonner, G. Effects of mindfulness-based stress reduction on medical and premedical students. J. Behav. Med. 21, 581-599.

Speca, M., Carlson, L.E., Goodey, E., Angen, M., 2000. A randomized, wait-list controlled clinical trial: the effect of a mindfulness meditation-based stress reduction program on mood and symptoms of stress in cancer outpatients. Psychosom. Med. 62, 613-622.

Sridevi, K., Krishna Rao, P.V., 1996. Yoga practice and menstrual distress. J. Indian Acad. Appl. Psychol. 22:47-54. 
Teasdale, J., Segal, Z.V., Williams, J.M.G., Ridgeway, V.A., Soulsby, J.M., Lau, M.A., 2000. Prevention of relapse/recurrence in major depression by mindfulness-based cognitive therapy. J. Consult. Clin. Psychol. 68, 615-623.

Unutzer, J., Klap, R., Sturm, R., Young, A.S., Marmon, T., Shatkin, J., Wells, K.B., 2000. Mental disorders and the use of the alternative medicine: results from a national survey. Am. J. Psychiatry 157, 1851-1857.

Vogel, C,M., Albin, R., Alberts, J.W., 1991. Lotus footdrop: sciatic neuropathy in the thigh. Neurology 41, 605-606.

Wang, J., Patten, S.B., Russell, M.L., 2001. Alternative medicine use by individuals with major depression. Can J Psychiatry 46, 528-533.

Woolery, A., Myers, H., Sternlieb, B., Zeltzer, L., 2004. A yoga intervention for young adults with elevated symptoms of depression. Altern. Ther. Health Med. $10(2), 60-63$.

Yorston, G.A., 2001. Mania precipitated by meditation: a case report and literature review. Ment. Health Relig. Cult. 4(2), 209-213. 